\begin{tabular}{|c|c|c|c|c|c|c|}
\hline \multirow{4}{*}{ Impact Factor: } & ISRA (India) & $=3.117$ & SIS (USA) & $=0.912$ & ICV (Poland) & $=6.630$ \\
\hline & ISI (Dubai, UAE & $=0.829$ & РИНЦ (Russia & $=\mathbf{0 . 1 5 6}$ & PIF (India) & $=1.940$ \\
\hline & GIF (Australia) & $=0.564$ & ESJI (KZ) & $=8.716$ & IBI (India) & $=4.260$ \\
\hline & JIF & $=1.500$ & SJIF (Morocco & $=5.667$ & OAJI (USA) & $=0.350$ \\
\hline
\end{tabular}

\begin{tabular}{|c|c|}
\hline \multicolumn{2}{|c|}{$\begin{array}{l}\text { SOI: } 1.1 / \mathrm{TAS} \text { DOI: } 10.15863 / \mathrm{TAS} \\
\text { International Scientific Journal } \\
\text { Theoretical \& Applied Science }\end{array}$} \\
\hline p-ISSN: 2308-4944 (print) & e-ISSN: 2409-0085 (online) \\
\hline Year: 2019 & Volume: 72 \\
\hline Published: 30.04 .2019 & http://T-Science.org \\
\hline
\end{tabular}

SECTION 31. Economic research, finance, innovation, risk management.
QR - Issue

QR - Article
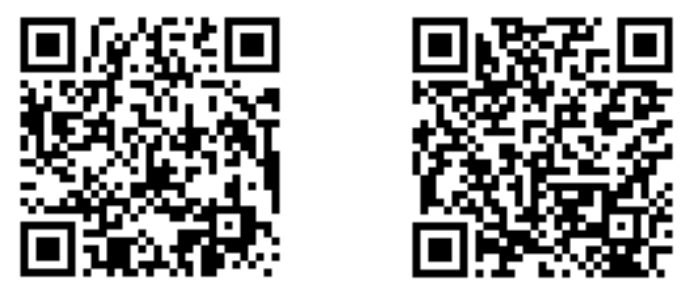

A.A. Hasanov

Doctor of Philosophy (Ph.D) on Economy,

Associated Professor,

Azerbaijan State Agrarian University, Head of the Department of Management and Agricultural Marketing asif hasanov@rambler.ru ORCID ID 0000-0001-8762-572

\title{
INVESTMENT IN "GREEN" ECONOMY - A STRATEGIC WAY OF ECONOMIC DEVELOPMENT IN THE REPUBLIC OF AZERBAIJAN
}

Abstract: This article is devoted to the topical issue - investment into the key sectors of the "green" economy. Green economy can be defined as a strategically designed network to use valuable natural resources and environment protection, providing of broad range of services and products, using "green" technologies, improving the living conditions and prosperity of humans by means of creation of a energy saving accommodation and enhancing work environment. The article deals with the current "green" economy directions and perspectives of its development. The necessary measures are being taken in the Republic of Azerbaijan in order to neutralize the negative environmental impact of the fuel-energy complex. As Azerbaijan is a sunny country, a particular interest has been increased to solar energy as well as geo-thermal wind bioenergy. The author of the article proposes how to percept green economy as development for the production and consumption of goods and services that sustain ecological safety and need serious investments into the "green" development.

Key words: investments, Green economy, renewable energy.

Language: Russian

Citation: Hasanov, A. A. (2019). Investment in "green" economy - a strategic way of economic development in the republic of Azerbaijan. ISJ Theoretical \& Applied Science, 04 (72), 570-575.

Soi: http://s-0-i.org/1.1/TAS-04-72-79 Doi: rossef https://dx.doi.org/10.15863/TAS.2019.04.72.79

\section{ИНВЕСТИРОВАНИЕ В ЗЕЛЁНУЮ ИНФРАСТРУКТУРУ - ПУТЬ СТРАТЕГИЧЕСКОГО РАЗВИТИЯ ЭКОНОМИКИ АЗЕРБАЙДЖАНСКОЙ РЕСПУБЛИКИ}

Аннотация: Статья посвящена актуальной проблеме - инвестированию в ключевые сектора «зелёной» экономики. Зелёная экономика может быть определена как стратегически спланированная сеть по использованию иенных природных ресурсов и охране окружающей среды, обеспечению широкого спектра услуг и продуктов, использованию «зелёных» технологий, по улучшению условий жизни и благосостояния людей путём создания энергосберегающего жилья и расширения рабочей средь. $B$ статье рассматриваются действующие направления «зелёной» экономики и перспективь её развития. В Азербайджанской Республике принимаются необходимые меры для нейтрализации негативного воздействия топливно-энергетического комплекса на окружаюшую среду. Повышен интерес к использованию солнечной энергии, так как Азербайджан - солнечная страна, а также к геотермальной, биоэнергетике энергии ветра. Автор даёт предложения к восприятию зелёной экономики как развитию производства и потребления товаров и услуг, которые обеспечивают экологическую безопасность и требующие серьёзные инвестиции в «зелёное» развитие.

Ключевые слова: инвестииии, «зелёная» экономика, возобновляемая энергия.

Введение

Азербайджан - страна с высоким потенциалом возобновляемых источников энергии. Экономически жизнеспособные и технически возможные возобновляемые источники энергии в стране в потенциале оцениваются в 26940 МВт, в том числе 3000 МВт ветровой энергии, 23040 МВт солнечной энергии, 


\begin{tabular}{|c|c|c|c|c|c|c|}
\hline \multirow{4}{*}{ Impact Factor: } & ISRA (India) & $=3.117$ & SIS (USA) & $=0.912$ & ICV (Poland) & $=6.630$ \\
\hline & ISI (Dubai, UAE & $=0.829$ & РИНЦ (Russia) & $=0.156$ & PIF (India) & $=1.940$ \\
\hline & GIF (Australia) & $=0.564$ & ESJI (KZ) & $=8.716$ & IBI (India) & $=4.260$ \\
\hline & JIF & $=1.500$ & SJIF (Morocco & $=5.667$ & OAJI (USA) & $=0.350$ \\
\hline
\end{tabular}

380 МВт биоэнергетики и 520 МВт горных реках. Потенциальная мощность гидроэнергетики оценивается экспертами в 40 млрд. киловатт-часов (рис.1). Несмотря на богатство энергоресурсов и признание в качестве экспортёра традиционных видов энергоносителей в мире, Азербайджан не использует в полной мере все источники энергии. Возобновляемые источники энергии в Азербайджане являются одной из ключевых целей политики энергетической безопасности страны в целях усиления их использования. Одним из основных шагов, предпринятых для эффективного использования потенциала возобновляемых источников энергии в нашей стране, стало принятие законопроекта [1]. Начиная с 2009 года, для расширения национальной энергетической безопасности в стране принимается ряд законодательных актов. Решения, принятые для эффективного использования потенциала возобновляемой энергии нашей страны, и реализованные проекты позволили добиться успеха в увеличении производства альтернативной и возобновляемой энергии. Запуск очередного поколения возобновляемых источников энергии привёл к новому этапу развития в энергетическом секторе и экономики в целом.

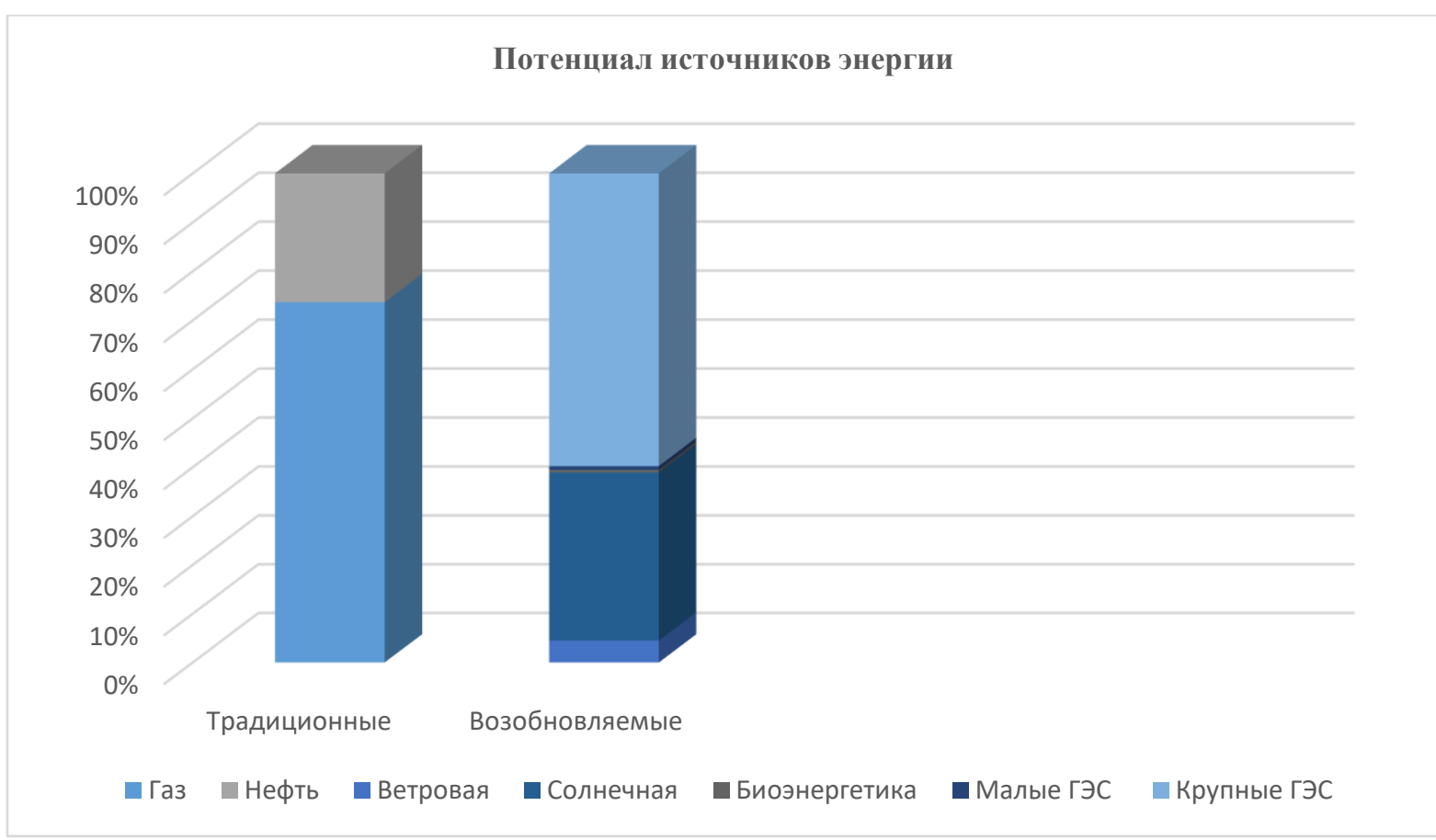

Рис.1 Прогнозируемый энергетический потенциал Азербайджанской Республики Составлено автором с использованием данных источника: [Электронный ресурс] http://www.biznesinfo.az/observer/dossier/params/ln/ru/article/94442 (дата обращчения 20.03.2019)

\section{Теория}

На протяжении более трёх десятилетий многие страны заняты реструктуризацией экономики, нацелены постепенно изменить её цвет (коричневый на зелёный). Изучая тенденции прошлого и настоящего опыта стран мира, практически использующих международный документ «Забота о Земле - стратегия устойчивого существования», отражающий всемирную стратегию охраны природы, провозгласившую несколько принципов устойчивого развития, один из которых создание национальных программ, обеспечивающих адекватное состояние экономической, экологической и социальной сфер [2].

Термин «зелёная экономика» Программы Организации Объединённых Наций по окружающей среде (ЮНЕП) определяется как экономика, которая способствует благосостоянию людей и социальной справедливости и в то же время снижает экологические риски.

Согласно расчётам различных экологических агентств развитых стран, спрос на природные ресурсы в 1961 году составлял 70\% от потенциала биологического восстановления Земли, спрос в 1980 - е годы превысил мощности Земли, а природные ресурсы, использованные к концу двадцатого века, уже составили $120 \%$ восстановительной способности Земли, то есть для восстановления израсходованных ресурсов требуется 1,2 всех не возобновляемых ресурсов Земли [3].

В связи с этим в развитых странах была введена концепция «зелёных» технологий, для 


\begin{tabular}{|c|c|c|c|c|c|c|}
\hline \multirow{4}{*}{ Impact Factor: } & ISRA (India) & $=3.117$ & SIS (USA) & $=0.912$ & ICV (Poland) & $=6.630$ \\
\hline & ISI (Dubai, UAE & $=0.829$ & РИНЦ (Russia) & $=0.156$ & PIF (India) & $=1.940$ \\
\hline & GIF (Australia) & $=0.564$ & ESJI (KZ) & $=8.716$ & IBI (India) & $=4.260$ \\
\hline & JIF & $=1.500$ & SJIF (Morocco & $=5.667$ & OAJI (USA) & $=0.350$ \\
\hline
\end{tabular}

того, чтобы использовать больше природных ресурсов, а также для защиты окружающей среды. «Зелёные» технологии - это технологии, которые используются природой и являются абсолютно безвредными или наносят минимальный ущерб окружающей среде. Эта концепция включает продукты, оборудование и системы, которые отвечают следующим критериям: минимизация деградации окружающей среды; снижение выбросов парниковых газов; содействие использованию возобновляемых источников энергии [4].

Зелёная экономика также может быть описана как новая концепция экономики или может быть определена как существенное дополнение человеческих и природных факторов к основам классической экономики.

Инвестирование в зелёную инфраструктуру имеет экономический смысл - одна и та же земельная площадь может обеспечить несколько выгод: предоставление нашему обществу целого ряда ценных, экономически важных товаров и услуг и здоровую экосистему, динамику которой определяет разнообразие в ней живых организмов. Утрата биоразнообразия принесёт скудные выгоды обществу в целом. Однако, если применять инвестиционные решения для улучшения зелёной инфраструктуры, то возможно, не только сохранить экосистему здоровой, но и реабилитировать деградировавшие места обитания, чтобы предоставить обществу качественные товары и услуги [5].

\section{Данные и методы}

Необходимость перехода к «зелёной» экономике во всех сферах жизни общества продиктована тем, что в результате экономического развития технологические инновации нуждаются в энергии и, с другой стороны, также наблюдается рост бытовых и промышленных отходов и сточных вод. Основными приоритетами являются управление этими областями, защита окружающей среды, благополучие людей в здоровой окружающей среде, использование природных ресурсов на благо населения мира.

Характеристикой насыщения количеством благ является валовой внутренний продукт на душу населения по паритету покупательной способности. В целом же, этот «показатель роста экономики» в прямом смысле отрицательно влияет на окружающую среду. К счастью, в последние десятилетия многие страны пересматривают так хорошо действующие и отлаженные временем пути развития экономики своих стран в пользу «зелёной экономики». И Азербайджан, как динамично развивающаяся в настоящее время страна, присоединился к этому течению, желая коренным образом изменить инфраструктуру экономики. В этом векторном направлении нашей Республике, обладающей одними возможностями и не имеющей других, по мнению автора статьи, надо двигаться. Новая модель экономического развития должна катализировать инвестиции и инновации и открыть новые возможности для создания экологически чистых продуктов.

Целью исследования является инвестирование в зелёные предприятия. Чтобы бизнес был зелёным, он должен соответствовать следующим принципам:

1) устойчивого развития, которое должно отразиться в бизнес-решениях;

2) производства экологически чистых продуктов, оказания услуг;

3) приверженности экологическим принципам в коммерческой деятельности.

Методами исследования, которыми пользовался автор статьи - анализ и обобщение специальной литературы, публикаций в периодических изданиях, посвященных зелёному росту, зелёной экономии, ресурсосбережению, зелёной логистики: складированию, транспортировке, упаковке, зелёной инфраструктуре [6].

\section{Полученные результаты}

В настоящее время общая мощность производства электроэнергии в нашей стране составляет 7144 МВт, электростанции с возобновляемыми источниками энергии, включая крупные гидроэлектростанции, - 1273 МВт, что составляет $18 \%$ от общей мощности. Имеются 21 гидроэлектростанция (11 малых гидроэлектростанций) общей мощностью 1134 МВт, введена в действие установка сжигания твёрдых бытовых отходов мощностью $37 \mathrm{MBT}, 4$ ветряные электростанции общей мощностью 66 МВт, 7 солнечных электростанций общей мощностью 34 МВт, работает 1 гибридная электростанция в Гобустане. Эти станции играют важную роль в электроснабжении населения и в обеспечении энергетической безопасности страны (рис.2). В то же время природный газ и другие не возобновляемые ресурсы, используемые для производства электроэнергии, сохраняются в немалом объёме.

Стратегический подход к обеспечению экологически чистой электроэнергии таков, что планируется до 2030 года ввести 420 МВт новых генерирующих мощностей на возобновляемых источниках энергии: при использовании энергии ветра 350 МВт, солнечной энергии 50 МВт и 20 МВт на биоэнергии (рис.3). В то же время прогнозируется высокий спрос на электроэнергию и планируется на ближайшие 10 лет увеличить долю возобновляемых источников энергии [7]. Реализация целей, изложенных в Стратегической 


\begin{tabular}{|c|c|c|c|c|c|c|}
\hline \multirow{4}{*}{ Impact Factor: } & ISRA (India) & $=3.117$ & SIS (USA) & $=0.912$ & ICV (Poland) & $=6.630$ \\
\hline & ISI (Dubai, UAE & $=0.829$ & РИНЦ (Russia) & $=0.156$ & PIF (India) & $=1.940$ \\
\hline & GIF (Australia) & $=0.564$ & ESJI (KZ) & $=8.716$ & IBI (India) & $=4.260$ \\
\hline & JIF & $=1.500$ & SJIF (Morocco & $=5.667$ & OAJI (USA) & $=0.350$ \\
\hline
\end{tabular}

дорожной карте, поможет увеличить это соотношение между спросом и предложением [8]. Потенциал нашей страны и меры, принимаемые для инвестирования, являются важнейшими факторами достижения целей.

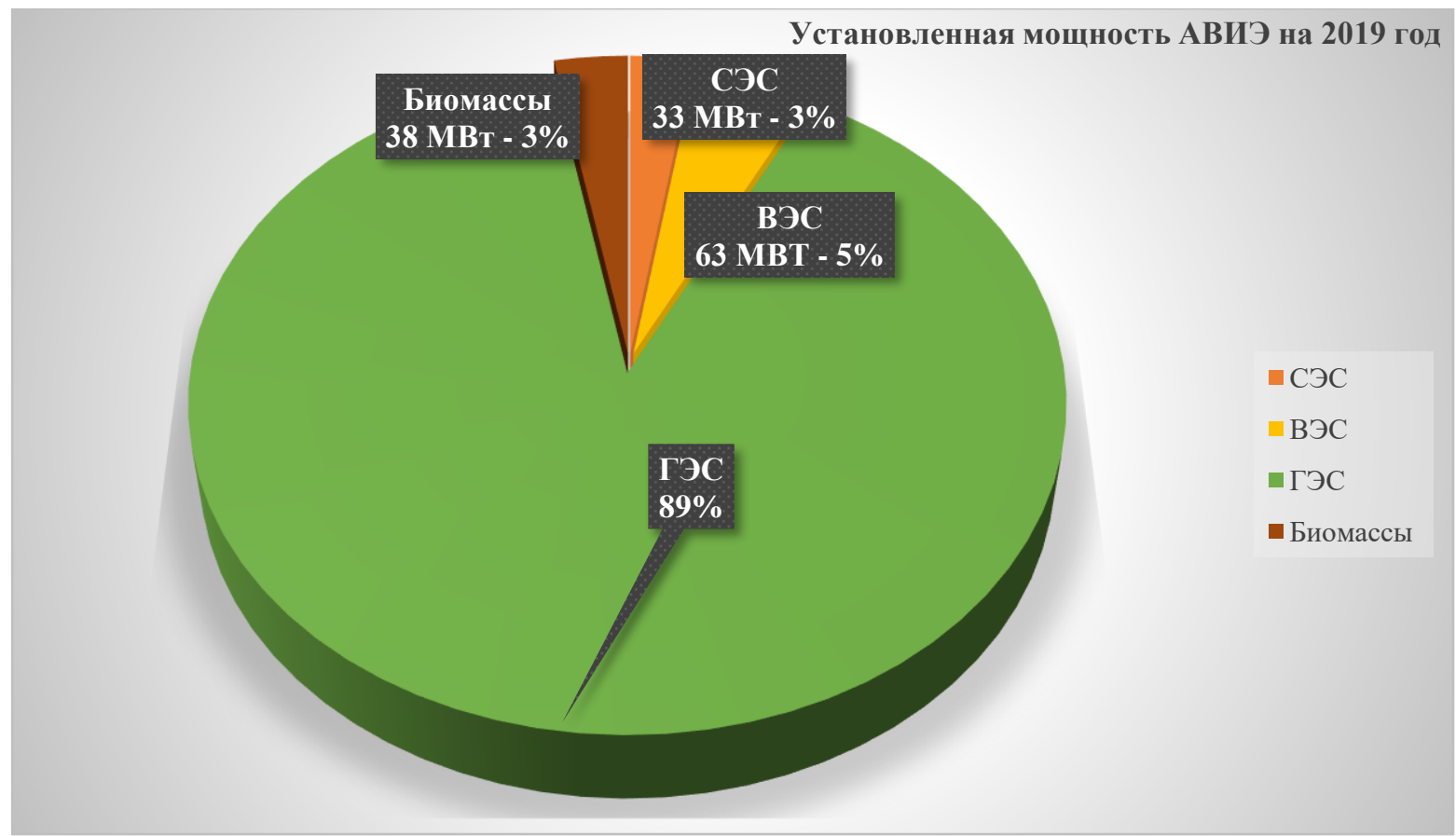

Рис 2. Электростанции АВИЭ в эксплуатации.

Составлено автором с использованием данных источника: [Электронный ресурс] http://interfax.az/view/752076 (дата обращения 20.03.2019)

Проект создания генерирующих мощностей в сфере АВИЭ до 2030 года

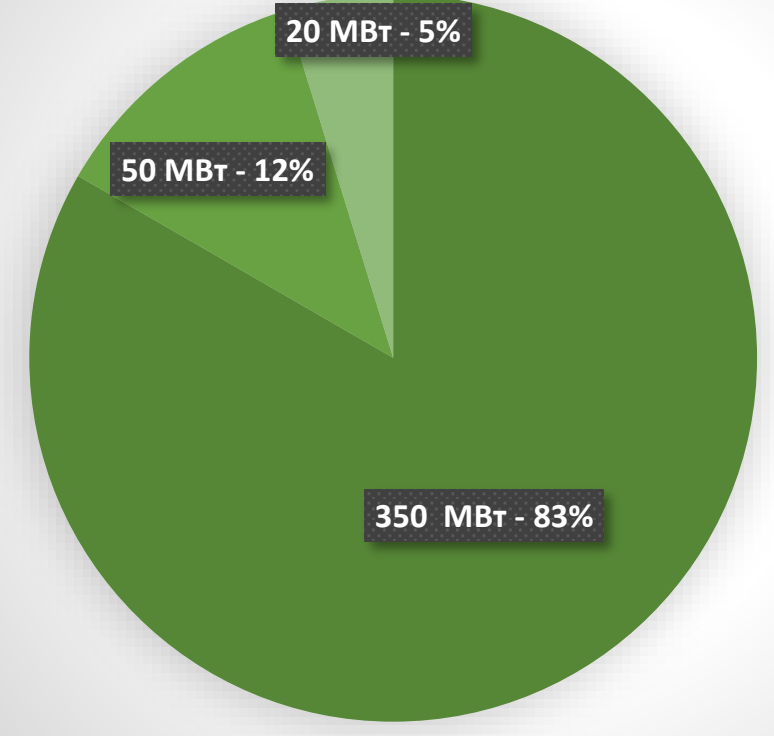

- $\mathrm{B \ni C}$

- СЭС

Биоэнергия

Рис 3. Электростанции по выработке энергии ветра, солнца и биомассы.

Составлено автором с использованием данных источника: [Электронный ресурс] http://interfax.az/view/752076 (дата обращения 20.03.2019)

Азербайджан является одной из стран, применяющих налоговые льготы для поддержания использования возобновляемых источников энергии. Так импорт оборудования, технологических средств юридическими лицами и индивидуальными предпринимателями, 


\begin{tabular}{|c|c|c|c|c|c|c|}
\hline \multirow{4}{*}{ Impact Factor: } & ISRA (India) & $=3.117$ & SIS (USA) & $=0.912$ & ICV (Poland) & $=6.630$ \\
\hline & ISI (Dubai, UAE & $=0.829$ & РИНЦ (Russia & $=0.156$ & PIF (India) & $=1.940$ \\
\hline & GIF (Australia) & $=0.564$ & ESJI (KZ) & $=8.716$ & IBI (India) & $=4.260$ \\
\hline & JIF & $=1.500$ & SJIF (Morocco & $=\mathbf{5 . 6 6 7}$ & OAJI (USA) & $=0.350$ \\
\hline
\end{tabular}

получившими документ о поощрении инвестиций, в порядке, установленном соответствующим органом исполнительной власти, в течение 7 лет с даты получения документа освобождаются на 50\% от таможенной пошлины и налога на добавленную стоимость. $50 \%$ заработка освобождается от налогов на имущество и земельного налога [9].

Запланированные шаги увеличили использование возобновляемых источников энергии в нашей стране, а также применение технологий в этой области. В технологическом парке города Сумгаита основан завод солнечных панелей и солнечных коллекторов с годовой производительностью 50 МВт. Помимо реализованных мероприятий, в будущем планируется реализовать множество проектов в области возобновляемых источников энергии. Проводится работа по наблюдению за измерениями для оценки потенциала этих проектов [10].

Анализ инвестиций в развитие зелёной экономики как в глобальном, так и местном масштабе показал, что сосредоточены они в основном в следующих областях:

1) наращивание потенциала - тренинги, консультационные услуги, техническая помощь;

2) финансирование услуг - гранты, финансирование проектов;

3) научно-исследовательские услуги применение базовых знаний, управление наукой;

4) информационные услуги - обмен информацией, развитие образования;

5) услуги трансфера технологий - обмен технологиями.

Роль фискальной политики в развитии зелёной экономики является решающей. У каждой страны есть свои фискальные инструменты. Эти инструменты включают налоговые льготы для потребления топлива; субсидии, способствующие более чистой деятельности в областях, которые являются экологически чистыми; финансовую помощь секторам с чистыми технологиями и устойчивой производственной деятельностью, и другие инструменты.

Прежде всего, зелёная инфраструктура предлагает интеллектуальное и целостное решение для управления природным капиталом. Решение текущих проблем односторонним подходом в значительной степени игнорирует сложные взаимосвязи между основными типами землепользования, такими как поселения, сельское хозяйство, транспорт и биоразнообразие. Зелёная инфраструктура предлагает динамичные, ориентированные на будущее инвестиционные решения, позволяющие решать разнообразные и часто конкурирующие проблемы землепользования и достигающие положительные побочные эффекты. Инвестиции в зелёную инфраструктуру способствуют появлению высококвалифицированных рабочих мест, способных восстановить и поддержать экосистему страны.

Одним из ключевых преимуществ зелёной инфраструктуры является её способность выполнять несколько функций в одной области. В отличие от большинства инфраструктур, которые имеют только одну цель, зелёная инфраструктура является многофункциональной. Зелёная инфраструктура предлагает беспроигрышные решения и выход из разных ситуаций с небольшими потерями, которые приносят пользу многим заинтересованным сторонам, а также широкой общественности. Зелёная инфраструктура способствует более устойчивому, ресурсосберегающему и эффективному развитию страны. Она может стать катализатором роста экономики, поскольку привлекает иностранных инвесторов, создаёт рабочие места, уменьшает экологические издержки и предлагает неоценимые преимущества для здоровья общества.

Стратегический подход к развитию зелёной инфраструктуры предполагает такие действия, как объединение заинтересованных сторон, которые вместе принимают решение о наилучшем использовании земли на местном уровне прозрачным и целостным способом. Однако значительные топливно-энергетические запасы, которыми обладает Азербайджан, и обеспечение населения природным газом может стать препятствием для развития альтернативной энергетики.

Менеджеры не оценивают потенциал энергетической эффективности компаний. Руководители компаний консервативно оценивают потенциал экономии энергии в размере $10-15 \%$, в то время как ведущие эксперты могут добиться экономии от 20 до $30 \%$. Азербайджанские компании используют ограниченные аудиты энергетических возможностей и резервов и недооценивают преимущества иностранного финансирования. Около $50 \%$ опрошенных компаний обнаружили и признали, что основной причиной неэффективности энергетического сбережения является нехватка средств. Однако лишь четверть азербайджанских компаний обратилась за иностранным финансированием. Отсюда можно сделать вывод, что слабое внешнее финансирование означает лишь одно, что меры, которыми могут воспользоваться компании для сбережения энергии дорогостоящие, а процедуры в области эффективного использования энергии трудоёмкие и сложные.

\section{Заключение}

Суммируя все это, следует отметить следующие варианты инструментов, которые 


\begin{tabular}{|c|c|c|c|c|c|c|}
\hline \multirow{4}{*}{ Impact Factor: } & ISRA (India) & $=3.117$ & SIS (USA) & $=0.912$ & ICV (Poland) & $=6.630$ \\
\hline & ISI (Dubai, UAE & $=0.829$ & РИНЦ (Russia & $=\mathbf{0 . 1 5 6}$ & PIF (India) & $=1.940$ \\
\hline & GIF (Australia) & $=0.564$ & ESJI (KZ) & $=8.716$ & IBI (India) & $=4.260$ \\
\hline & JIF & $=1.500$ & SJIF (Morocco & $=5.667$ & OAJI (USA) & $=0.350$ \\
\hline
\end{tabular}

можно использовать в зеленой налоговобюджетной политике: 1) инструменты экологического налога (например, налог на выбросы углерода); 2) штраф за интенсивное загрязнение; 3) зеленые субсидии для поощрения положительной экологической деятельности (например, «питательный» рецепт), гранты, займы; 4) устранение предоставления субсидий на экологически вредные виды деятельности; 5) прямые государственные расходы (например, организация научно-исследовательской деятельности для экологически чистой инфраструктуры или чистых технологий).

Привлечение частных инвестиций ускорит развитие регионов, будет способствовать полной интеграции зелёной инфраструктуры в стратегические цели регионального развития для того, чтобы стать стандартным компонентом территориального развития. Проведение политики местного управления во развитию зелёной инфраструктуры могут применяться в различных масштабах: создание дождевых садов, проницаемых тротуаров, зелёных крыш, плантаторов инфильтрации, энергосберегающих жилых и служебных помещений.

В Азербайджане «зелёная» экономика, использование альтернативных источников энергии, подготовка специалистов в этой области и обучение потребителей энергии являются серьёзными проблемами, которые можно преодолеть привлечением инвестиций.

Существуют некоторые меры, которые побуждают менеджеров повысить свою конкурентоспособность с целью достижения более высокой энергетической эффективности: создание более широкого спектра информации об энергетической эффективности, подготовка плана и проведение организационных мер по снижению потребления энергии внутри компании, таких как осведомлённость и поощрение сотрудников за более эффективное использование энергии. Оценка экономической информации стратегии энергетической эффективности должна подвести компании к принятию инвестиционных решений по привлечению иностранных инвестиций.

\section{References:}

1. (2004). Official website of the President of Azerbaijan Ilham Aliyev Presidential Decree on the approval of the state program "On the use of alternative and renewable energy sources in the Republic of Azerbaijan" Retrieved April 08, 2019, from https://en.president.az/

2. (2015). Report of the United Nations Conference on Environment and Development, Rio de Janeiro, June 3-14, 1992 A/CONF.151/26/Rev.1 (Vol. I), pp. 3-7. Retrieved April 03, 2019, from http://gbpp.org/wp-

content/uploads/2015/10/211020152.pdf

3. (2013). Secretariat energy charter. Review of Azerbaijan's energy efficiency policy. pp.7189.

4. (n.d.). Bizim Yol [Our Road] - social-political, socio-economic online newspaper. Retrieved 2019,

from https://www.bizimyol.info/az/news/66667.html

5. (n.d.). Eine Grüne Infrastruktur für Europa. pp.7-9. Retrieved 2019, from http://ec.europa.eu/environment/nature/ecosyste ms/docs/GI-Brochure-210x210-DE-web.pdf

6. Ral'f Fyuks (2016). Zelonaya revolyutsiya Ekonomicheskiy rost bez ushcherba dlya ekologii. Moscow: Izdatel'skiy dom «Al'pina non-fikshn», pp.5-6. [Ralph Fuks Green
Revolution Economic growth without damage to the environment. Moscow: Publishing house "Alpina non-fiction" 159p. P. 5-6] (In Russ)

7. (2019). Market Analysis Azerbaijan. p.11.

8. (2017). Chief Editor Doctor of Economic Sciences Vusal Musaev Center for Analysis of Economic Reforms and Communiuations// Overview of the economic reforms of Azerbaijan //March 2017 Strategic road maps on national economy and main sectors of economy. p.16. Retrieved 2019, from http://iqtisadiislahat.org/store//media/

documents/

islahatlar_icmali/Mart\%20buraxilisi/ru/strateji \%20yol\%20x\%C9\%99rit\%C9\%99si\%20-ru.pdf

9. (n.d.). Tax Code of the Republic of Azerbaijan article 199.7 - 199.11

10. Aliyev, R. A., \& Ismailova, G. F. (2015). Zelonaya ekonomika $\mathrm{v}$ Azerbaydzhanskoy Respublike: predposylki i napravleniya razvitiya. Internet-zhurnal «Naukovedeniye»ISSN 2223-5167 Tom 7 № 6 doi: $10.15862 / 107 E V N 615$ ["Green economy" in the Republic of Azerbaijan: preconditions and directions of development. Internet-journal "Naukovedenie"] http://naukovedenie.ru/PDF/107EVN615pdf 